\title{
Fixed combination of irbesartan and hydrochlorothiazide in the management of hypertension
}

\author{
Peter Bramlage \\ Institute for Cardiovascular \\ Pharmacology and Epidemiology, \\ Mahlow, Germany
}

\begin{abstract}
Approximately $25 \%$ of the adult population worldwide is hypertensive and thus at risk of cardiovascular morbidity and mortality. Despite the availability of many antihypertensive drugs, at least $50 \%$ of patients do not achieve blood pressure (BP) targets and thus remain at increased cardiovascular risk. Fixed-dose (FD) irbesartan/hydrochlorothiazide (HCTZ) is an antihypertensive combination therapy approved for the treatment of patients whose BP is not adequately controlled on monotherapy and for initial treatment of patients likely to need multiple drugs to achieve their BP goal. The efficacy and tolerability of FD irbesartan/HCTZ has been demonstrated in both patient populations in large multicenter studies. In patients failing antihypertensive monotherapy, FD irbesartan/HCTZ (150/12.5 mg) has been shown to be more effective than FD valsartan/HCTZ (80/12.5 mg) and at least comparable to FD losartan/HCTZ (50/12.5 mg). In patients with moderate or severe hypertension receiving FD irbesartan/HCTZ as initial therapy, this combination achieved more rapid BP reductions compared with irbesartan monotherapy and enabled a greater proportion of patients with severe hypertension to achieve their BP target. FD irbesartan/HCTZ is thus a valuable addition to the clinician's armamentarium for the management of hypertension and should help more patients achieve their BP target.

Keywords: blood pressure control, blood pressure target, combination therapy, angiotensin receptor blockers
\end{abstract}

\section{Management issues in treating hypertension}

Hypertension is a major cause of morbidity and mortality and an important public health challenge worldwide. It has been estimated that hypertension is responsible for approximately two-thirds of all strokes and 50\% of heart attacks worldwide. ${ }^{1}$ In addition, hypertension causes 7.1 million premature deaths per year worldwide and is responsible for $4.5 \%$ of the global burden of disease. ${ }^{1}$ This startling impact of hypertension on health worldwide in part reflects the high prevalence of hypertension. According to a recent review of published literature, approximately a quarter of the adult population worldwide (26.4\%) was hypertensive in 2000 and this is expected to increase to $29.2 \%$ by $2025 .{ }^{2}$ Appropriate management of hypertension is therefore an important priority worldwide, especially given the impact that effective blood pressure (BP) control can have on morbidity and mortality.

Effective BP control has been shown to significantly reduce morbidity and mortality, as demonstrated in a meta-analysis of data from trials of active antihypertensive treatment compared with placebo. ${ }^{3}$ According to this analysis, active antihypertensive treatment in hypertensive patients significantly reduced the risk of fatal and nonfatal stroke by approximately $40 \%$ and coronary heart disease (CHD) by approximately $15 \%$, while all-cause mortality was reduced by approximately $15 \%$ and cardiovascular mortality by approximately $20 \%$. In addition, a meta-analysis of data from 61 prospective observational studies has shown that the risk of vascular mortality is strongly and directly related 
to BP in middle-aged and elderly individuals. A 2-mmHg reduction in systolic blood pressure (SBP) has been reported to result in a $7 \%$ reduction in the risk of ischemic heart disease and a $10 \%$ reduction in the risk of stroke mortality, while larger reductions in SBP produce even greater reductions in vascular morbidity and mortality. ${ }^{4}$ These data provide a strong rationale for the use of antihypertensive therapy to reduce the burden of morbidity and mortality associated with this highly prevalent condition.

However, despite the availability of a large number of antihypertensive agents, BP control remains inadequate in many patients. For example, a study which analyzed data collected in surveys conducted in the 1990s reported rates of BP control ranging from $5 \%$ to $10 \%$ in European countries, $17 \%$ in Canada and 29\% in the US. ${ }^{5}$ More recently, Wang et $\mathrm{al}^{6}$ reported rates of $\mathrm{BP}$ control of $27 \%$ to $40 \%$ in five European countries (France, Germany, Italy, Spain, the UK) and $53 \%$ in the US, suggesting that rates of BP control are improving. However, over half of patients still fail to reach BP targets, and are therefore at increased risk of cardiovascular morbidity and mortality. It is mainly SBP targets that are not reached ${ }^{7}$ and systolic hypertension is most frequent in the elderly. ${ }^{8}$ It has recently been suggested that control of SBP alone should be the guide to treatment. ${ }^{9}$

Poor patient compliance with antihypertensive therapy and circumstances that do no allow physicians to adhere to treatment guidelines are frequent problems and are often the reason for patients not reaching their BP goal. For example, a recent survey of primary care physicians in 17 countries worldwide reported that $72 \%$ of physicians said that patients are not compliant with antihypertensive treatment when asked why over $50 \%$ of patients fail to achieve their BP targets. ${ }^{10}$ A US study of patients receiving free medical care found that fewer than a third of patients on antihypertensive medication were still taking their prescribed medication a year later. ${ }^{11}$ Another study investigating the rate of discontinuation or change in antihypertensive therapy in patients newly prescribed a course of antihypertensive medication has reported that $50 \%$ to $60 \%$ of patients discontinue or change therapy within 6 months. ${ }^{12}$ Improving compliance is therefore an important task for all healthcare providers. ${ }^{13}$ An important move to overcome this issue has been the development of fixed-dose (FD) combination therapies, since most patients require combination therapy to achieve BP targets. ${ }^{14}$

\section{Fixed-dose combinations}

Most guidelines suggest that initial combination treatment should include a thiazide diuretic and either an angiotensin receptor blocker (ARB), an angiotensin-converting enzyme inhibitor (ACE-I), a calcium channel blocker (CCB), or a beta-blocker. ${ }^{14,15}$ In addition, for patients with chronic renal disease or type 2 diabetes, combinations including an ARB or ACE-I are recommended. ${ }^{15-20}$ FD combinations are now available consisting of combinations of different antihypertensive drugs which fit these recommendations, including: an ARB plus a thiazide diuretic; an ARB plus a calcium antagonist, an ACE inhibitor plus a thiazide diuretic; a beta-blocker with a diuretic; and an ACE inhibitor plus a calcium antagonist. ${ }^{14}$

The usefulness of FD ARB/hydrochlorothiazide (HCTZ) combinations in effectively treating hypertension, including difficult-to-treat and severely hypertensive patients, has been demonstrated for several different ARBs. ${ }^{14}$ Promising results have also been reported for FD combinations regarding improvements in clinical endpoints, as well as achieving BP targets.

There is evidence to suggest that combination therapy can be better tolerated than certain monotherapies. The use of low-dose combination therapy is associated with fewer adverse events than with the higher doses of single agents that would be required to achieve the same level of BP control. ${ }^{21}$ In addition, combining HCTZ with an ARB attenuates the hypokalemic and fasting glucose-modifying effects of HCTZ. ${ }^{22}$ As discussed in a later section, there is evidence to suggest that FD combinations are also associated with better compliance. ${ }^{23-25}$

In the recent ACCOMPLISH study (Avoiding Cardiovascular Events in Combination Therapy in Patients Living with Systolic Hypertension), HCTZ was compared with amlodipine on the basis of benazepril treatment in patients with compelling indications for the use of CCBs (eg, any atherosclerotic disease). Patients with a compelling indication for the use of HCTZ (eg, heart failure) were excluded. Cardiovascular morbidity and mortality were reduced by $20 \%$ with the ACE-I/CCB combination. ${ }^{26}$ In addition, in this study, BP control rates were $75 \%$ in the ACE-I/CCB arm and $72 \%$ in the ACE-I/HCTZ arm. These BP control rates are better than those reported in other recent major trials in hypertensive patients. ${ }^{26}$ The study design may have favored the ACE-I/CCB arm as the primary endpoint included measures of myocardial ischemia in which CCBs are more effective and excluded heart failure in which diuretics are more effective. ${ }^{14,18,26}$

FD combinations of benazepril/HCTZ and benazepril/ amlodipine have been reported to significantly reduce BP and albuminuria ( $\mathrm{p}<0.0001$ ), in patients with type 2 diabetes and mild hypertension, although a significantly 
greater reduction in albuminuria was achieved with the ACE inhibitor/HCTZ combination. ${ }^{27}$ In another study, the combination of trandolapril/verapamil was found to be superior to losartan/HCTZ in reducing new-onset diabetes in patients with hypertension and impaired glucose tolerance titrated to achieve a SBP of $<130 \mathrm{mmHg}$; the incidence of new-onset diabetes was $11.0 \%$ for trandolapril/verapamil vs $26.6 \%$ for $\operatorname{losartan} / \mathrm{HCTZ}(\mathrm{p}=0.002){ }^{28}$

FD ARB/CCB combinations (amlodipine with either olmesartan or valsartan) are also effective in treating hypertension. ${ }^{29,30} \mathrm{BP}$ control rates of $74 \%$ have been reported after 16 weeks of valsartan/amlodipine $160 / 10 \mathrm{mg}$ treatment, ${ }^{29}$ and of $53 \%$ after 8 weeks of olmesartan/amlodipine 20/10 mg treatment. ${ }^{30}$ Combining a $\mathrm{CCB}$ with an $\mathrm{ARB}$ may reduce the incidence of peripheral edema as seen with olmesartan/ amlodipine compared with amlodipine alone: ${ }^{30}$ the incidence of edema was reduced from $13.0 \%$ to $36.8 \%$ for amlodipine monotherapy (dose range $5-10 \mathrm{mg}$ ) to $18.0 \%$ to $26.5 \%$ when olmesartan was combined with amlodipine (dose range 10/5 mg-40-10 mg), and was lowest for olmesartan monotherapy (dose range 10-40 mg, 9.9\%-18.5\%).

This review focuses on the benefits and tolerability of the FD ARB/HCTZ combination of irbesartan/HCTZ.

\section{Overview of pharmacology, mode of action, and pharmacokinetics of irbesartan and HCTZ, alone and in combination}

A valuable FD combination therapy that has received approval in Europe and the US is FD irbesartan/HCTZ. FD irbesartan/HCTZ is approved for the treatment of patients whose BP is not adequately controlled on irbesartan or HCTZ alone (US and European license), ${ }^{31,32}$ and in the US (but not in Europe) for initial treatment of patients likely to need multiple drugs to achieve their BP goals. ${ }^{31} \mathrm{FD}$ irbesartan/HCTZ is available as $150 / 12.5 \mathrm{mg}, 300 / 12.5 \mathrm{mg}$ and $300 / 25 \mathrm{mg}$ and therapy should be started with the low dose and uptitrated. This paper reviews the efficacy and safety data for FD irbesartan/HCTZ, both for patients inadequately controlled on antihypertensive monotherapy and as initial therapy for patients with moderate or severe hypertension.

FD irbesartan/HCTZ has been developed in response to promising results reported for combination therapy with both agents given as individual tablets, as discussed in later sections of this paper, ${ }^{22,33,34}$ and the fact that combining irbesartan and HCTZ is a logical option for patients requiring combination therapy since the 2 agents act via distinct mechanisms of action. Irbesartan exerts its antihypertensive effects by inhibiting the activation of angiotensin II type 1 $\left(\mathrm{AT}_{1}\right)$ receptors. This elicits vasodilation and reduces the secretion of vasopressin and aldosterone, thereby reducing BP. HCTZ is a thiazide diuretic. It exerts its antihypertensive effects by inhibiting $\mathrm{Na}^{+} / \mathrm{Cl}^{-}$reabsorption from the distal convoluted tubules in the kidney. By reducing osmotic pressure in this way, HCTZ reduces the reabsorption of water in the distal convoluted tubules and thereby reduces plasma volume and cardiac output. The combined effect of these actions is to reduce BP.

Both irbesartan and HCTZ are active following oral administration and do not require biotransformation. They are efficiently absorbed following oral administration, having an oral bioavailability of $60 \%$ to $80 \%$ (irbesartan) and $50 \%$ to $80 \%$ (HCTZ), and peak concentrations are reached 1.5 to 2 hours (irbesartan) and 1 to 2.5 hours (HCTZ) after administration. ${ }^{32}$ The intake of food does not affect the bioavailability of either agent.

Irbesartan exhibits linear dose-proportional pharmacokinetics over the dose range 10 to $600 \mathrm{mg}$. Repeated dosing results in limited accumulation $(<20 \%)$ and steady state concentrations are achieved within 3 days with once-daily administration. ${ }^{35}$ Irbesartan is largely excreted unchanged $(80 \%-85 \%)$, but is also metabolized in the liver via glucuronide conjugation and oxidation. Irbesartan and its metabolites are eliminated largely in the feces $(80 \%)$ but also in the urine $(20 \%)$. Its terminal elimination half-life is 11 to 15 hours, which compares favorably with most other ARBs. ${ }^{36}$

Pharmacokinetic data on the irbesartan/HCTZ combination are not available but co-administration of irbesartan and HCTZ has no effect on the pharmacokinetics of either drug, ${ }^{37}$ but increases the BP lowering activity observed, ${ }^{32}$ as discussed further in the following section of this review.

\section{Efficacy of FD irbesartan/HCTZ combination}

The benefits of combining irbesartan and HCTZ were demonstrated in an early study using a matrix design to investigate the effects of combinations of different doses of irbesartan $(0,37.5,100$ or $300 \mathrm{mg})$ plus $\operatorname{HCTZ}(0,6.25,12.5$ or $25 \mathrm{mg})$ on BP. ${ }^{22}$ The reduction in DBP by 8 weeks ranged from $3.5 \mathrm{mmHg}$ for placebo, to 5.1 to $8.3 \mathrm{mmHg}$ for HCTZ monotherapy, 7.1 to $10.2 \mathrm{mmHg}$ for irbesartan monotherapy, and 8.1 to $15.0 \mathrm{mmHg}$ for combination therapy, clearly indicating a synergistic effect for the addition of irbesartan to HCTZ and vica versa. Similarly, the proportion of responders (ie, patients achieving normalized DBP or trough DBP decreased 
by $\geq 10 \mathrm{mmHg}$ ) at 8 weeks increased from $24 \%$ for placebo, to $36 \%$ to $53 \%$ for HCTZ monotherapy, $35 \%$ to $58 \%$ for irbesartan monotherapy, and $44 \%$ to $80 \%$ for combination therapy.

\section{FD irbesartan/HCTZ in patients failing on antihypertensive monotherapy}

The benefits of FD irbesartan/HCTZ combination therapy have subsequently been demonstrated in a number of trials in patients with mild hypertension who failed to achieve BP control with monotherapy, and in patients with moderate or severe hypertension. The efficacy data for the main studies are summarized in Table 1.

The efficacy of FD irbesartan/HCTZ 300/25 mg was first demonstrated in a study of hypertensive patients who had failed to gain BP control after at least 2 months of high-dose monotherapy or low-dose combination therapy. ${ }^{38}$ In this study, 57 patients with SBP/DBP $\geq 140 / 90 \mathrm{mmHg}$ received FD irbesartan/HCTZ 300/25 mg once daily for 12 weeks. A significant reduction in clinic and ambulatory mean BP was observed at the end of the study period compared with baseline. Mean 24-hour SBP was reduced from 146.0 to $123.3 \mathrm{mmHg}$ and mean 24-hour DBP was reduced from 89.8 to $76.5 \mathrm{mmHg}$, both differences were statistically significant ( $p<0.001$ ). In addition, therapy achieved a mean lowering of ambulatory SBP/DBP at peak of 25.2/14.7 $\mathrm{mmHg}$ and 22.3/12.3 $\mathrm{mmHg}$ at trough. Thus FD irbesartan/HCTZ was found to produce clinically meaningful reductions in SBP/ DBP in patients failing to achieve BP targets on monotherapy or low-dose combination therapy.

FD irbesartan/HCTZ at the lower dose of 150/12.5 mg has shown superior efficacy to other ARB/HCTZ combinations in comparative trials. The COmparative Study of Efficacy of
Irbesartan/HCTZ with Valsartan/HCTZ Using Home Blood Pressure Monitoring in the TreAtment of Mild-to-Moderate Hypertension (COSIMA) study, compared the BP-lowering effects of irbesartan/HCTZ 150/12.5 mg and FD valsartan/ HCTZ 80/12.5 mg. ${ }^{39}$ Patients $(n=800)$ with untreated or uncontrolled mild-to-moderate essential hypertension initially received HCTZ $12.5 \mathrm{mg}$ for 5 weeks. 464 patients failing to achieve BP control (SBP $<140 \mathrm{mmHg}$ ) at the end of this period were randomized to receive FD irbesartan/ HCTZ 150/12.5 mg or FD valsartan/HCTZ 80/12.5 mg once daily for 8 weeks. Effects on BP were assessed by both office BP measurements and home BP monitoring (HBPM). Irbesartan/HCTZ produced greater reductions in both office and home BP compared with valsartan/HCTZ over the treatment period; according to HBPM a reduction in SBP of $13.0 \mathrm{mmHg}$ was achieved with irbesartan/HCTZ compared with $10.6 \mathrm{mmHg}$ with valsartan/HCTZ $(\mathrm{p}=0.0094)$, while the reduction in DBP achieved was $9.5 \mathrm{mmHg}$ for irbesartan/ HCTZ compared with $7.4 \mathrm{mmHg}$ for valsartan/HCTZ $(\mathrm{p}=0.0007)$. In addition, the BP normalization rate (SBP/ $\mathrm{DBP}<135 / 85 \mathrm{mmHg}$ ) according to HBPM was significantly greater with irbesartan/HCTZ than with valsartan/HCTZ (50.2\% vs 33.2\%, p=0.0003).

FD irbesartan/HCTZ 150/12.5 $\mathrm{mg}$ has also been shown to be more efficacious than FD losartan/HCTZ 50/12.5 mg. ${ }^{40} \mathrm{In}$ this study, patients with mild-to-moderate hypertension were randomized to receive FD irbesartan/HCTZ 150/12.5 mg $(\mathrm{n}=16)$ or FD losartan/HCTZ 50/12.5 mg $(\mathrm{n}=15)$ for 4 weeks. While both treatments significantly reduced BP from baseline, the reduction in ambulatory DBP was significantly greater with irbesartan/HCTZ than with losartan/HCTZ; the adjusted mean change from baseline in 24-hour ambulatory DBP was $-10.5 \mathrm{mmHg}$ with irbesartan/HCTZ compared

Table I Summary of efficacy data for main studies of fixed-dose irbesartan/hydrochlorothiazide (HCTZ)

\begin{tabular}{|c|c|c|c|c|}
\hline Study & Patients, $\mathbf{n}$ & $\begin{array}{l}\text { Duration of therapy and } \\
\text { irbesartan/HCTZ dose }\end{array}$ & $\begin{array}{l}\text { Mean reduction in } \\
\text { SBP/DBP, } \mathrm{mmHg}\end{array}$ & $\begin{array}{l}\text { SBP/DBP normalization } \\
\text { rate, } \%\end{array}$ \\
\hline Bobrie et $\mathrm{al}^{39}$ & $\begin{array}{l}\text { Failing monotherapy, } \\
n=464\end{array}$ & 8 weeks; I50/I2.5 mg & $\begin{array}{l}\text { I3.0/9.5 vs } 10.6 / 7.4 \text { for } \\
\text { valsartan/HCTZ, } \mathrm{p}<0.0 \mathrm{I}^{\mathrm{a}}\end{array}$ & $\begin{array}{l}50.2 \text { vs } 33.2 \text { for valsartan/ } \\
\text { HCTZ, } P=0.0003^{\circ}\end{array}$ \\
\hline INCLUSIVE ${ }^{41}$ & $\begin{array}{l}\text { Failing monotherapy, } \\
\mathrm{n}=844\end{array}$ & 18 weeks; titrated to $300 / 25 \mathrm{mg}$ & $\begin{array}{l}21.5 / 10.4(p<0.001 \text { vs } \\
\text { baseline })\end{array}$ & $69^{c}$ \\
\hline Neutel et a $\left.\right|^{46}$ & $\begin{array}{l}\text { Severe hypertension, } \\
n=695\end{array}$ & 5 weeks; titrated to $300 / 25 \mathrm{mg}$ & & $\begin{array}{l}34.6 \text { vs } 19.2 \text { for irbesartan } \\
\text { monotherapy, } \mathrm{p}<0.000 \mathrm{I}^{\mathrm{d}}\end{array}$ \\
\hline Neutel et a $\left.\right|^{48}$ & $\begin{array}{l}\text { Moderate hypertension, } \\
n=538\end{array}$ & 8 weeks; titrated to $300 / 25 \mathrm{mg}$ & $\begin{array}{l}27.1 / 14.6 \text { vs } 22.1 / 11.6 \text { for } \\
\text { irbesartan monotherapy, } \\
P<0.005\end{array}$ & $\begin{array}{l}53.4 \text { vs } 40.6 \text { for irbesartan } \\
\text { monotherapy, } p=0.0254^{d}\end{array}$ \\
\hline
\end{tabular}

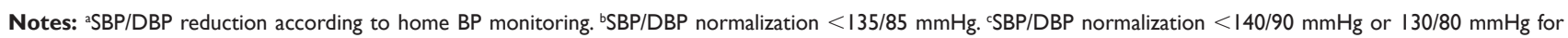

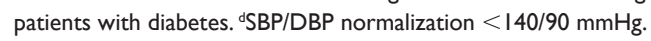


with $-6.1 \mathrm{mmHg}$ with losartan/HCTZ, $(\mathrm{p}=0.001)$. There was also a non-significant trend towards a greater reduction in mean 24-hour ambulatory SBP with irbesartan/HCTZ (-16.0 vs $-11.1 \mathrm{mmHg}$ ). The response rate (ie, percentage of patients achieving a mean 24-hour ambulatory DBP of $<90 \mathrm{mmHg}$ or a reduction in mean 24-hour ambulatory DBP of $\geq 10 \mathrm{mmHg}$ ) was slightly higher for FD irbesartan/HCTZ but the difference was not statistically significant $(86.7 \%$ vs $80.0 \%)$.

The Irbesartan/Hydrochlorothiazide Blood Pressure Reductions in Diverse Patient Populations (INCLUSIVE) trial, extended the findings of previous irbesartan/HCTZ trials by evaluating the efficacy of low and high FD irbesartan/ HCTZ in a broad range of patients, including many in which BP goal attainment is particularly challenging, for example, the elderly, African Americans, and patients with type 2 diabetes mellitus and/or metabolic syndrome. ${ }^{41}$ This was a large multicenter prospective open-label single-arm study. 844 patients with uncontrolled SBP (140-159 $\mathrm{mmHg}$ or 130-159 mmHg for patients with type 2 diabetes) on antihypertensive monotherapy were recruited from 119 centers in the USA. Patients initially discontinued previous antihypertensive therapy and received placebo for 4-5 weeks. They then received HCTZ $12.5 \mathrm{mg}$ for 2 weeks followed by FD irbesartan/HCTZ 150/12.5 mg for 8 weeks and FD irbesartan/HCTZ 300/25 for 8 weeks (ie, active treatment was given for a total of 18 weeks). Changes in BP were assessed over the period of active treatment, ie, 18 weeks.

Over the course of the study, the mean reductions in SBP and DBP were 21.5 and $10.4 \mathrm{mmHg}$, respectively, and both were statistically significant ( $\mathrm{p}<0.001$ ). At Week 18 , mean $\mathrm{SBP} / \mathrm{DBP}$ was $132.9 \pm 13.8 / 81.1 \pm 9.7 \mathrm{mmHg}$. In addition, $77 \%$ of patients achieved their SBP goal $(<140 \mathrm{mmHg}$ or $<130 \mathrm{mmHg}$ for patients with type 2 diabetes), $83 \%$ achieved their DBP goal $(<90 \mathrm{mmHg}$ or $<80 \mathrm{mmHg}$ for patients with type 2 diabetes), and 69\% achieved SBP and DBP goals. Thus over three-quarters of patients previously uncontrolled on monotherapy achieved SBP and/or DBP control with FD irbesartan/HCTZ (Table 1).

Several subgroup analyses of the INCLUSIVE data have confirmed the efficacy of the treatment regimen in patients whose hypertension is often difficult to control. Of the patients included in this study, 30\% $(n=254)$ had type 2 diabetes, 46\% $(\mathrm{n}=386)$ had metabolic syndrome (MS) and $21 \%(\mathrm{n}=177)$ had both MS and type 2 diabetes. A subgroup analysis of patients with type 2 diabetes $(n=227)$ found that the mean change from baseline in SBP/DBP for this subgroup was $-18.2 /-8.7 \mathrm{mmHg}{ }^{42}$ This reduction was only slightly less than for the total study population and was statistically significant compared with baseline ( $\mathrm{p}<0.001)$. In addition, $56 \%$ of diabetes patients achieved their SBP goal of $130 \mathrm{mmHg}, 63 \%$ achieved their DBP goal of $80 \mathrm{mmHg}$, and $40 \%$ achieved both SBP and DBP goals. Analysis of data for the subgroup of patients with MS $(n=345)$ yielded a similar reduction in BP compared with the total study population (change from baseline in SBP/DBP, $-21.0 /-10.4 \mathrm{mmHg}$ ) and both were statistically significant $(\mathrm{p}<0.001)$. In this subgroup, 73\% achieved the SBP goal, 77\% achieved the DBP goal and 61\% achieved both SBP and DBP goals. For patients with both MS and type 2 diabetes $(n=157), 57 \%$ achieved the SBP goal, 59\% the DBP goal and 39\% reached both SBP and DBP goals. Thus FD irbesartan/HCTZ was found to achieve SBP goals in approximately three-quarters of patients with MS and over half of patients with type 2 diabetes, despite the more stringent BP goals in patients with type 2 diabetes. ${ }^{42} \mathrm{BP}$ control is particularly important for these patients who are at increased cardiovascular risk.

The possible impact of race/ethnicity and age on the response to FD irbesartan/HCTZ was also assessed. ${ }^{43,44}$ While almost two-thirds of patients in the INCLUSIVE trial were Caucasian ( $\mathrm{n}=515,61 \%)$, almost a quarter were African American $(n=191,23 \%)$ and 14\% $(n=119)$ were Hispanic/Latino. Mean changes in SBP/DBP were similar for all subgroups and were statistically significant compared with baseline $(\mathrm{p}<0.001)$. The percentages of patients achieving SBP/DBP goals were also similar for the different racial/ ethnic subgroups: Caucasian, 70\%; African-American, 66\%; Hispanic/Latino, $65 \% .{ }^{43}$ A quarter of patients included in the study were elderly (aged 65 years or older, $n=212,25 \%$ ). ${ }^{44}$ Analysis of data for this subgroup showed that the mean reductions in SBP and DBP achieved were similar to those in the total study population $(23.0 / 10.9 \mathrm{mmHg}$; $\mathrm{p}<0.001)$. At the end of the study, mean SBP/DBP was $134.0 \pm 14.7 / 75.1 \pm$ $8.4 \mathrm{mmHg}$, and dual SBP/DBP goals were achieved in $72 \%$ of patients. This response rate is similar to that achieved in the total study population (69\%) and shows that FD irbesar$\tan / \mathrm{HCTZ}$ is highly efficacious in elderly as well as younger patients. A secondary analysis of data from the INCLUSIVE study found that higher baseline SBP, female sex, type 2 diabetes, and statin therapy were predictive of additional BP-lowering, suggesting that FD irbesartan/HCTZ may be a particularly appropriate choice of therapy in such patients. ${ }^{45}$

\section{FD irbesartan/HCTZ as initial therapy in moderate or severe hypertension}

As patients with moderate or severe hypertension are likely to require 2 or more antihypertensive medications to 
attain BP goal, there is a clear rationale for treatment with combination therapy from the outset. The value of initial FD irbesartan/HCTZ in patients with moderate or severe hypertension has been investigated in 2 large multicenter studies, the RAPiHD moderate and severe trials.

The RAPiHD severe study, a randomized, double-blind, active-control, multicenter study, investigated the efficacy of FD irbesartan/HCTZ in untreated patients with severe hypertension (DBP $\geq 110 \mathrm{mmHg}$ ) or patients with a DBP of $\geq 100 \mathrm{mmHg}$ while receiving antihypertensive monotherapy. ${ }^{46}$ Patients initially received placebo for 1 week after which all patients with a DBP of $\geq 110 \mathrm{mmHg}$ were randomized 2:1 to receive FD irbesartan/HCTZ or irbesartan monotherapy (as active control). FD irbesartan/HCTZ was initiated at a dose of $150 / 12.5 \mathrm{mg}$ and force-titrated to $300 / 25 \mathrm{mg}$ at the end of the first week of treatment $(n=468)$, while irbesartan was initiated at a dose of $150 \mathrm{mg}$ and forcetitrated to $300 \mathrm{mg}(\mathrm{n}=227)$. Therapy at the higher dose was given for 6 weeks.

At Week 5, significantly more patients on combination therapy achieved a DBP of $<90 \mathrm{~mm} \mathrm{Hg}$ (the primary endpoint) compared with monotherapy recipients $(47.2 \%$ vs $33.2 \% ; \mathrm{p}=0.0005)$. Similarly, the percentage of patients achieving dual BP goals (SBP/DPB $<140 / 90 \mathrm{mmHg}$ ) was significantly greater for FD irbesartan/HCTZ: $34.6 \%$ vs $19.2 \%, \mathrm{p}<0.0001$ (Table 1). Indeed, a significant difference in achievement of the DBP goal was evident after only 1 week of therapy ( $15.2 \%$ vs $9.2 \%, p=0.03)$. In addition, the mean reduction in SBP/DBP was greater with FD combination therapy; at Week 5, the mean difference between combination and monotherapy in DBP and SBP was $4.7 \mathrm{mmHg}$ and $9.7 \mathrm{mmHg}$, respectively ( $\mathrm{p}<0.0001$ ). Thus initial therapy with FD irbesartan/HCTZ achieved more rapid BP reductions than irbesartan monotherapy in patients with severe hypertension, and in so doing significantly reduced their exposure to severe hypertension.

Of the patients included in the RAPiHD severe study, approximately a quarter $(\mathrm{n}=199,29 \%)$ had SBP $\geq 180 \mathrm{mmHg}$ at baseline. Analysis of data for this subgroup of patients showed that a reduction in SBP/DBP of $41 / 23 \mathrm{mmHg}$ was achieved with combination therapy at Week 5 compared with $29 / 19 \mathrm{mmHg}$ with monotherapy ( $p<0.0001$ for SBP and $p=0.0071$ for DBP).${ }^{47}$ In addition, as early as 1 week after the start of therapy, more than $70 \%$ of patients receiving combination therapy were no longer in the stage 3 hypertension category.

The RAPiHD moderate study enrolled patients with moderate hypertension, defined as SBP of 160 to $179 \mathrm{mmHg}$ and DBP of $<110 \mathrm{mmHg}$ in untreated patients; or $\mathrm{SBP} \geq 150$ to $<180 \mathrm{mmHg}$ and $\mathrm{DBP} \geq 95$ to $<110 \mathrm{mmHg}$ in patients uncontrolled on monotherapy. ${ }^{48}$ Following a 3-week placebo washout period, patients were randomized 3:1:1 to irbesartan/ HCTZ 300/25 mg ( $=328)$, irbesartan 300 mg monotherapy $(\mathrm{n}=106)$ or HCTZ monotherapy $25 \mathrm{mg}(\mathrm{n}=104)$. Treatment was initiated at half dose, with forced titration to full dose after 2 weeks followed by 10 further weeks of treatment. The primary efficacy endpoint was the change in SBP after 8 weeks of active therapy.

FD irbesartan/HCTZ was found to induce a significantly greater reduction in SBP and DBP than either monotherapy. The mean reduction in SBP was $27.1 \mathrm{mmHg}$ with irbesartan/ HCTZ, compared with $22.1 \mathrm{mmHg}$ with irbesartan monotherapy $(\mathrm{p}=0.0016)$ and $15.7 \mathrm{mmHg}$ with HCTZ $(\mathrm{p}<0.0001)$, while the mean reductions in DBP from baseline to Week 8 were $14.6 \mathrm{mmHg}$ in the irbesartan/HCTZ group compared with $11.6 \mathrm{mmHg}$ in the irbesartan group $(\mathrm{p}=0.0013)$ and $7.3 \mathrm{~mm} \mathrm{Hg}$ in the HCTZ group $(\mathrm{p}<0.0001)$. Both the rate of decline and the total degree of decline achieved were greatest with irbesartan/HCTZ and least with HCTZ. In addition, a significantly greater percentage of patients reached a treatment goal of SBP $<140 \mathrm{mmHg}$ and DBP $<90 \mathrm{mmHg}$ by Week 8 with irbesartan/HCTZ (53.4\%), compared with irbesartan $(40.6 \% ; \mathrm{p}=0.0254)$ and HCTZ $(20.2 \%$; $\mathrm{p}<0.0001)$ alone (Table 1). Thus FD irbesartan/HCTZ treatment achieved more rapid BP reduction than irbesartan monotherapy or HCTZ monotherapy in patients with moderate hypertension.

A post hoc pooled analysis of data from both this study and the randomized study in patients with severe hypertension found that the need for initial combination therapy increased with increasing baseline BP and lower BP goals across a range of BP levels spanning moderate and severe hypertension (Figure 1). ${ }^{49}$ For example, the probability of achieving a post-treatment value of $<140 \mathrm{mmHg}$ for a patient with a baseline SBP of $185 \mathrm{~mm} \mathrm{Hg}$ was approximately $30 \%$ with irbesartan/HCTZ and 16\% with irbesartan monotherapy, while for patients with a baseline SBP of $160 \mathrm{mmHg}$, the respective probabilities were $66 \%$ and $48 \%$.

Another post hoc pooled analysis of data from both of these studies reported that $\mathrm{SBP} / \mathrm{DBP}$ reductions (27-31/16-22 mmHg) were similar regardless of age, obesity, and type 2 diabetes status (Figure 2). ${ }^{50} \mathrm{SBP} / \mathrm{DBP}$ reductions with FD irbesartan/HCTZ were, however, greater in high- vs low-risk patients $(30.4 / 22.1 \mathrm{mmHg}$ vs $28.4 / 15.6 \mathrm{mmHg})$. When adjusted for factors including baseline age, BMI, type 2 diabetes, sex, race, cholesterol, target organ damage, and acute coronary syndrome, mean reductions in SBP were 


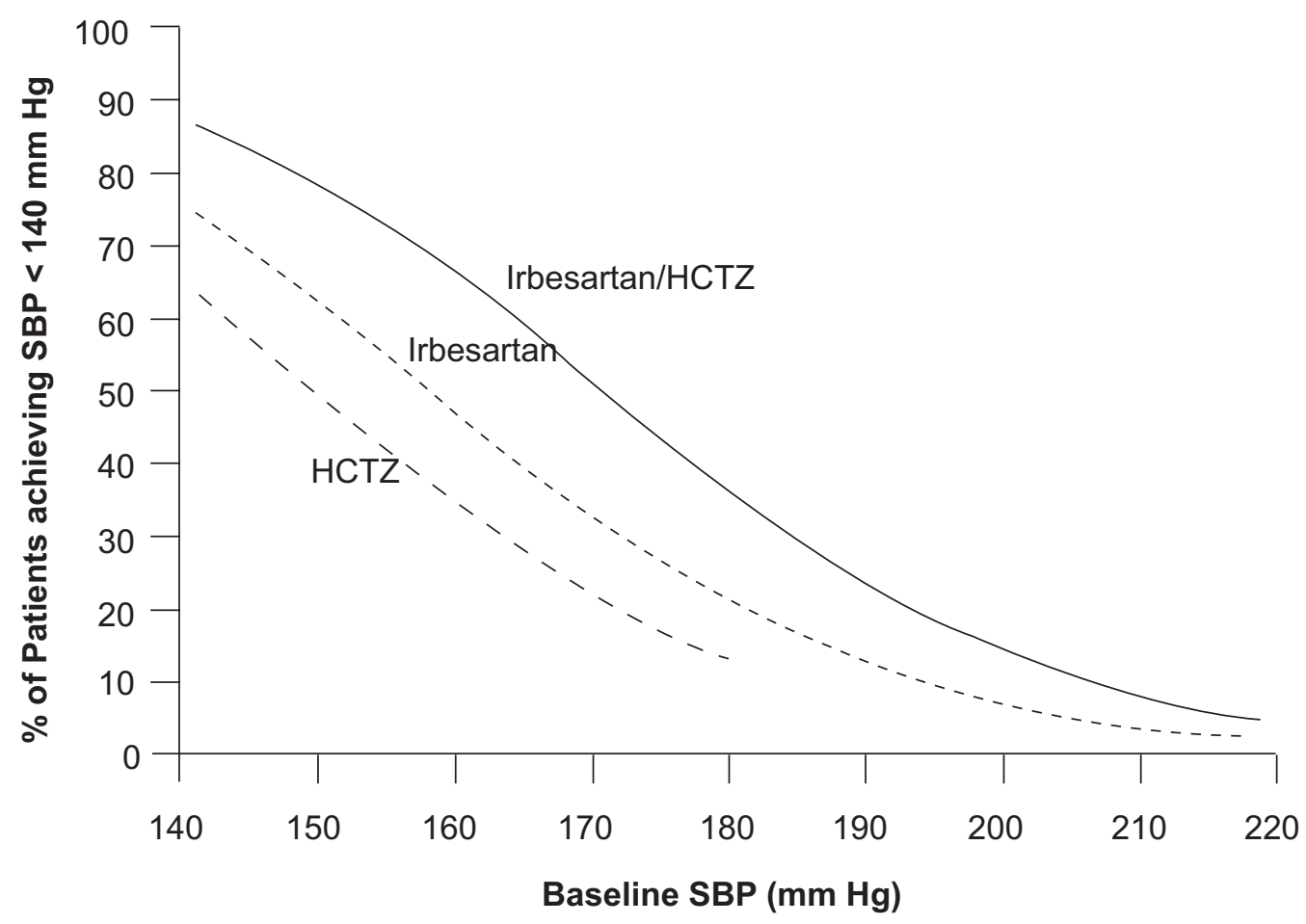

Figure I Probability of achieving a SBP $<140 \mathrm{mmHg}$ at Weeks $7 / 8$ across a range of baseline SBP following treatment with irbesartan/hydrochlorothiazide (HCTZ), irbesartan, and HCTZ. Results from the RAPiHD study. Reproduced with permission from Franklin S, Lapuerta P, Cox D, Donovan M. Initial combination therapy with irbesartan/ hydrochlorothiazide for hypertension: an analysis of the relationship between baseline blood pressure and the need for combination therapy. J Clin Hypertens (Greenwich). 2007; 9(I2 Suppl): I5-22.59 Copyright (C) 2007 John Wiley and Sons, Inc.

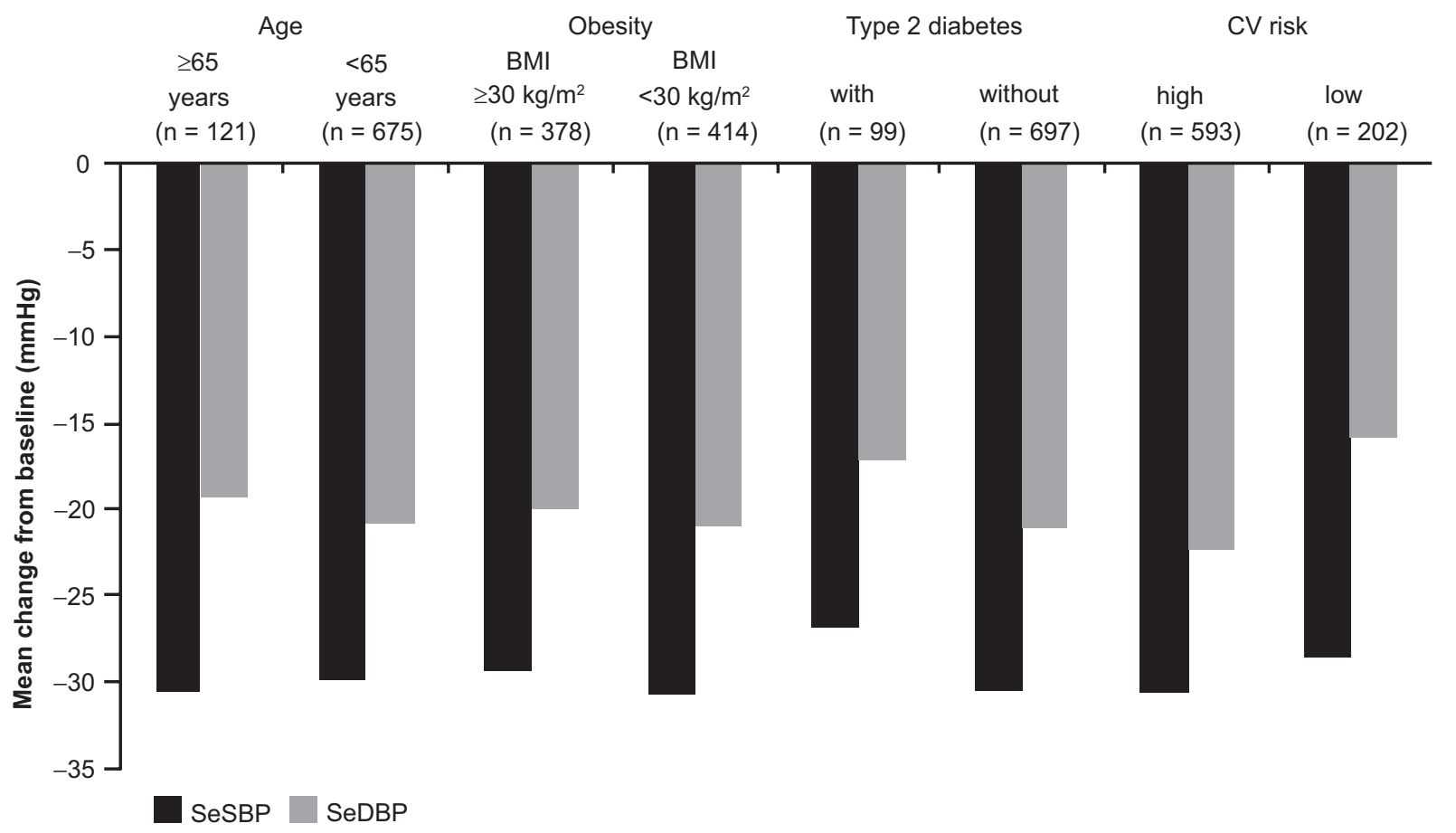

Figure 2 Mean reductions from baseline in SBP and DBP following initial fixed-dose irbesartan/hydrochlorothiazide (HCTZ) $300 / 25$ mg treatment, according to age, body mass index (BMI), type 2 diabetes, and cardiovascular (CV) risk. Results from the RAPiHD study. Reproduced with permission from Weir MR, Neutel JM, Bhaumik A, Obaldia ME, Lapuerta P. The efficacy and safety of initial use of irbesartan/hydrochlorothiazide fixed-dose combination in hypertensive patients with and without high cardiovascular risk. J Clin Hypertens (Greenwich). 2007; 9 (I2 Suppl):23-30. ${ }^{60}$ Copyright @ 2007 John Wiley and Sons, Inc. 
significantly higher in patients aged 65 years or older than in those younger than 65 years $(24.6 \mathrm{vs} 21.0 \mathrm{mmHg}$; difference, $3.6 \mathrm{mmHg} ; \mathrm{p}=0.015$ ).

Taken together, the results from the 2 RAPiHD studies indicate the value of starting treatment with FD irbesartan/ HCTZ in patients with moderate or severe hypertension.

\section{Studies on the effectiveness of irbesartan/ HCTZ in primary care}

Further evidence for the efficacy of FD irbesartan/HCTZ for the treatment of hypertension in patients uncontrolled on monotherapy and as initial therapy in patients with moderate or severe hypertension comes from the results of a Chinese study, several observational studies and two post-marketing studies.

A multicenter, open-label, single-arm study in Chinese patients has reported on the efficacy of FD irbesartan/HCTZ in patients $(\mathrm{n}=968)$ with mild-to-moderate hypertension. ${ }^{51}$ Patients received FD irbesartan/HCTZ 150/12.5 mg for the first 2 weeks and the dose was increased to 300/12.5 mg (after 2 weeks) and 300/25 mg (after 4 weeks) if required to achieved a DBP of $<85 \mathrm{mmHg}$. Treatment was given for 8 weeks. Of the patients who completed the study, 69\% received irbesartan/HCTZ 150/12.5 mg, 23\% received the intermediate dose level (300/12.5 $\mathrm{mg})$ and $8 \%$ received the highest dose level (300/25 mg). After 8 weeks, a mean reduction in SBP/DBP of 22.0/16.1 mmHg was achieved $(\mathrm{p}<0.01)$ and BP control was achieved in $84 \%$ of patients.

Two German studies have reported on the benefits of irbesartan/HCTZ in patients with hypertension and diabetes. In one observational study involving 9057 patients with hypertension and diabetes, the improvement in BP control was assessed over a 6-month period in patients receiving irbesartan or irbesartan/HCTZ. ${ }^{52}$ At baseline, only $20 \%$ of patients had SBP levels within target (ie, $<140 \mathrm{mmHg}$ ) and $57 \%$ had DBP levels within target (ie, $<90 \mathrm{mmHg}$ ). However, at 6 months, BP control rates had improved to $63 \%$ for SBP and 93\% for DBP. In the second observational study, patients with hypertension and type 2 diabetes $(n=31793)$ were switched from previous antihypertensive therapy to irbesartan (38\%) or irbesartan/HCTZ (61\%). ${ }^{53}$ Effects on BP were assessed after 3 months on irbesartan therapy. Mean SBP and DBP were reduced by $22.5 \mathrm{mmHg}$ and $10.7 \mathrm{mmHg}$, respectively, while SBP normalization (SBP $<140 \mathrm{mmHg}$ ) and DBP normalization (DBP $<90 \mathrm{mmHg}$ ) was achieved in $43 \%$ and $74 \%$ of patients, respectively. In addition, mean albuminuria decreased by $27.7 \mathrm{mg} / \mathrm{dL}$. The results of these 2 observational studies thus confirm the benefit of
irbesartan/HCTZ in patients with hypertension and diabetes reported in the INCLUSIVE study and suggest that irbesartan and irbesartan/HCTZ can help achieve good BP control rates in routine clinical practice.

Further evidence for the benefits of FD irbesartan/HCTZ in daily clinical practice comes from a 3-month, prospective, open-label, multicenter, phase IV study of irbesartan or irbesartan/HCTZ in 72,479 hypertensive patients $(92 \%$ of whom were overweight or obese) in 6989 general practices across Germany. ${ }^{54}$ Over the course of the 3-month study, a mean reduction in SBP/DBP of 23/12 $\mathrm{mmHg}$ was achieved and $48 \%$ of patients achieved BP normalization (SDP/DBP $<140 / 90 \mathrm{mmHg}$ ). In addition, $79 \%$ of patients met their individual treatment goals, as defined by their physician.

Finally, another study has assessed the effect of irbesartan and irbesartan/HCTZ on BP in 14,200 patients with uncontrolled hypertension with or without the MS. ${ }^{55,56}$ Both irbesartan and irbesartan/HCTZ produced significant reductions in SBP/DBP over the 9-month study period (irbesartan monotherapy, 26.8/13.3 mmHg, $\mathrm{p}<0.0001$; irbesartan/HCTZ, $27.9 / 14.2 \mathrm{mmHg}, \mathrm{p}<0.0001$ ), and BP normalization was achieved by $66 \%$ of patients receiving monotherapy and $79 \%$ of those receiving irbesartan/HCTZ. Approximately twothirds $(n=9281,65 \%)$ of patients included in the study had MS. Reductions in SBP/DBP achieved with monotherapy and combination therapy in this subgroup of patients were similar to those for the total study population (irbesartan monotherapy, 26.3/13.0 mmHg, $\mathrm{p}<0.0001$; irbesartan/HCTZ: 27.5/14.1 mmHg, $\mathrm{p}<0.0001)$. Reductions in cardiovascular risk factors were also observed in patients with MS.

The results from these large multicenter studies provide further evidence for the benefits of irbesartan/HCTZ in the management of BP, both in patients with hypertension alone and those with other cardiovascular risk factors including diabetes, MS and obesity.

\section{Clinical significance of SBP/DBP reductions}

The results of these studies show that irbesartan/HCTZ, used either to uptitrate from HCTZ monotherapy or as initial combination therapy, is highly effective for reducing SBP/DBP and achieving SBP/DBP goals. Achievement of such SBP/ DBP reductions can be expected to translate into significant improvements in clinical endpoints. ${ }^{57}$ Analysis of data from 29 randomized trials including 162,341 patients, showed that the risk of major cardiovascular events was reduced by interventions to reduce $\mathrm{BP}$ and that greater risk reductions 
were produced by antihypertensive regimens that targeted lower BP goals. ${ }^{57}$ In addition to the benefits associated with $\mathrm{BP}$ reductions, there is evidence to suggest that early achievement of BP reductions can produce greater reductions in stroke risk compared with delayed reductions, as observed in the VALUE (Valsartan Antihypertensive Long-term Use Evaluation) study. ${ }^{58}$ Analysis of data from this study showed that achieving BP control (SBP $<140 \mathrm{mmHg}$ ) within the first 6 months of the study was associated with significant benefits for subsequent major outcomes, including the risk of fatal and nonfatal cardiac events, fatal and nonfatal stroke, and all-cause death. In addition, achieving a BP response after just 1 month of treatment (defined as having no increase in BP in patients switched from previous therapy or achieving a decrease in SBP of $\geq 10 \mathrm{mmHg}$ in previously untreated patients) predicted for a reduced risk of cardiac and stroke events, and improved survival. This suggests that the rapid achievement of BP goals with FD ARB/HCTZ combinations is likely to significantly improve clinical endpoints compared with initial therapy with monotherapy.

\section{Safety and tolerability of irbesartan/ HCTZ combination}

It is well established that both HCTZ and irbesartan are well tolerated, and further studies have demonstrated that the addition of irbesartan to HCTZ and vice versa does not increase the incidence of adverse events. For example, in the 8-week study of Kochar et $\mathrm{al}^{22}$ in which patients received fixed combinations of irbesartan $(0,37.5,100$ or $300 \mathrm{mg})$ plus HCTZ
$(0,6.25,12.5$, or $25 \mathrm{mg})$, there was no significant difference in the incidence of commonly occurring adverse events between placebo, irbesartan monotherapy or irbesartan/ HCTZ combination therapy, and no dose-related adverse events were observed. Indeed, for a number of common adverse events, such as headache, irbesartan monotherapy and irbesartan/HCTZ were associated with a lower incidence of events than placebo. Also, the addition of irbesartan to HCTZ reversed HCTZ-induced hypokalemic effects and the increases in serum uric acid levels seen with HCTZ.

The adverse event rates for the major trials with FD irbesartan/HCTZ are presented in Table 2. In the INCLUSIVE trial, FD irbesartan/HCTZ 150/12.5 mg and irbesartan/HCTZ $300 / 25 \mathrm{mg}$ were found to be well tolerated over the 18 weeks of therapy (Table 2). ${ }^{41}$ Only dizziness and hypotension occurred more frequently during treatment with irbesartan/ HCTZ than with placebo (dizziness: placebo, 1\%; irbesartan/ HCTZ 150/12.5 mg, 2\%; irbesartan/HCTZ 300/25 mg, 3\%; hypotension: placebo, 0\%; irbesartan/HCTZ 150/12.5 mg, $0.1 \%$; irbesartan/HCTZ 300/25 mg, 1\%). No patients were discontinued from the study because of adverse events.

Safety and tolerability is a critical consideration in aggressive hypertensive therapy which can be associated with hypotension, syncope, headache and hypokalemia. However, in patients with severe hypertension ${ }^{46}$ or with moderate hypertension, ${ }^{48}$ starting treatment with FD irbesartan/HCTZ was as well tolerated as starting with irbesartan monotherapy. The adverse event and discontinuation rates are given in Table 2. In patients with moderate hypertension, 7 of the

Table 2 Safety data for main studies of fixed-dose irbesartan/hydrochlorothiazide (FD irbesartan/HCTZ): incidence of adverse events

\section{FD irbesartan/HCTZ}

Serious adverse event

Initial therapy in patients with severe hypertension ${ }^{46} \mathrm{n}=695$

Any adverse event

Discontinuation due to adverse event

Serious adverse event

Initial therapy in patients with moderate hyperten $\operatorname{sion}^{48} \mathrm{n}=538$

Any adverse event

Treatment-related adverse event

Discontinuation due to adverse event

Serious adverse event

${ }^{a}$ Of the 6 serious adverse events, only I was treatment related.

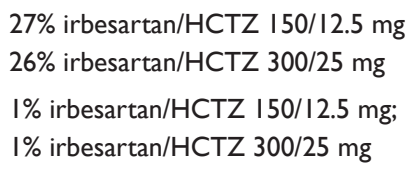

$27 \%$ irbesartan/HCTZ I50//2.5 mg $26 \%$ irbesartan/HCTZ 300/25 mg

I\% irbesartan/HCTZ I50//2.5 mg;

I\% irbesartan/HCTZ 300/25 mg

Irbesartan

monotherapy

$\begin{array}{ll}30 \% & 36 \% \\ 1.9 \% & 2.2 \% \\ 0.2 \% & 0.4 \% \\ & \\ 47 \% & 45 \% \\ 14 \% & 11 \% \\ 6.7 \% & 3.8 \% \\ 1.8 \%^{\mathrm{a}} & 0 \%\end{array}$


22 patients receiving combination therapy withdrew due to dizziness or hypotension but these events occurred primarily following forced titration in patients in whom BP was already controlled. ${ }^{48}$ In patients with severe hypertension, there was no syncope reported during the study, and the incidence of hypotension was $<1 \%$ in patients taking FD irbesartan/HCTZ combination therapy. ${ }^{46}$

In comparator trials, FD irbesartan/HCTZ had a similar adverse event profile to losartan/HCTZ ${ }^{40}$ and valsartan/ HCTZ.${ }^{39}$ Long-term safety data for patients receiving irbesar$\tan$ /HCTZ (although not as fixed-dose combination therapy) also support the favorable safety profile. ${ }^{33,34}$

In summary, accumulating safety data for irbesartan/ HCTZ combination therapy indicate that this ARB/ HCTZ antihypertensive combination is well tolerated by patients with hypertension; most adverse events are of mild or moderate intensity and transient in duration. In general, there is no evidence of an increase in the incidence of adverse effects as therapy is uptitrated, with the possible exception of dizziness and hypotension. However, the overall incidence of all individual adverse events is low. The incidence of adverse events with irbesartan/HCTZ appears to be similar to that for irbesartan monotherapy, while compared with HCTZ monotherapy, irbesartan/HCTZ appears to be better tolerated. This reflects the fact that HCTZ decreases serum potassium levels in a dose-related manner. However, this effect is less pronounced with the addition of increasing doses of irbesartan, and irbesartan $300 \mathrm{mg}$ appears to provide greatest benefit in reversing the hypokalemic effects of HCTZ. In addition, HCTZ $25 \mathrm{mg}$ results in a small increase in serum uric acid, but the addition of irbesartan reduces this effect. Thus no clinically significant occurrences of electrolyte imbalance have been observed in trials with irbesartan/HCTZ combination therapy or with irbesartan monotherapy. In conclusion, irbesartan/HCTZ is well tolerated and has a similar safety profile to that of irbesartan monotherapy.

\section{Adherence and patient acceptance of FD irbesartan/HCTZ}

Rapid and effective reduction of BP in hypertensive patients helps to prevent major cardiovascular events but patient nonadherence to antihypertensive medication often hinders the attainment of their optimal BP goal, as already discussed. FD irbesartan/HCTZ offers the important advantage of reducing the number of tablets to be taken by a patient and may therefore be expected to improve compliance and hence the efficacy of antihypertensive therapy over therapy with an ARB and HCTZ as separate tablets. Indeed the benefits of combination therapy in a single tablet over receiving medications as individual tablets in terms of improved compliance have clearly been demonstrated in three studies of persistence with antihypertensive therapy. One study retrospectively compared persistence for patients prescribed enalapril/HCTZ as a single pill or enalapril plus a diuretic as separate pills, and for patients prescribed lisinopril/HCTZ or lisinopril plus a diuretic as separate pills. At 12 months after the initial prescription, the percentage of patients persisting with therapy was $18.8 \%$ higher for lisinopril/HCTZ compared with lisinopril plus a diuretic and $21.7 \%$ higher for enalapril/HCTZ compared with enalapril plus a diuretic. These differences were statistically significant $(\mathrm{p}<0.05)$. Two further studies have determined patient persistence with FD amlodipine/benazepril or an ACE-I plus a CCB. ${ }^{20,24}$ Gerbino et $\mathrm{al}^{20}$ reported a persistence rate of $87.9 \%$ for FD amlodipine/benazepril compared with $69.2 \%$ for prescription of separate tablets, a difference that was statistically significant $(\mathrm{p}<0.0001)$, while Dickson et $\mathrm{al}^{24}$ also reported a statistically significant difference in favor of FD combination therapy in their study in elderly patients (63.4\% vs 49.0\%, p < 0.0001).

\section{Conclusions}

FD irbesartan/HCTZ has been shown to be effective for producing BP control in patients failing on antihypertensive monotherapy and as initial therapy in patients with moderate or severe hypertension who often require multiple agents to achieve BP control. It is effective in patients with type 2 diabetes, MS, and elderly patients as well as younger patients, and the response is similar regardless of race/ethnicity. In patients with severe or moderate hypertension, initial treatment with FD irbesartan/ HCTZ achieves more rapid BP reductions than either agent as monotherapy and enables a greater proportion of subjects with severe hypertension to achieve BP targets. This is likely to be of significant therapeutic benefit in such patients since studies have shown that a more rapid achievement of BP reductions predicts for better cardiovascular outcomes. FD irbesartan/ HCTZ is well tolerated, as for irbesartan monotherapy, and appears to reduce the incidence of hypokalemia and raised serum uric acid levels observed with HCTZ. The ARB/HCTZ combination therapies have an important role in the management of hypertension in clinical practice.

\section{Acknowledgments}

Editorial support for this article was provided by PPSI/ Pam Milner and was funded by Bristol-Myers Squibb and sanofi-aventis. The author retains sole responsibility for the content of this manuscript. 


\section{Disclosures}

The author has received a number of research grants from pharamaceutical companies, including sanofi-aventis.

\section{References}

1. WHO, facts and figures. World Health Organization. 2008.

2. Kearney PM, Whelton M, Reynolds K, Muntner P, Whelton PK, He J. Global burden of hypertension: analysis of worldwide data. Lancet. 2005;365(9455):217-223.

3. Cifkova R, Erdine S, Fagard R, et al. Practice guidelines for primary care physicians: $2003 \mathrm{ESH} / \mathrm{ESC}$ hypertension guidelines. J Hypertens. 2003;21(10):1779-1786.

4. Lewington S, Clarke R, Qizilbash N, Peto R, Collins R. Age-specific relevance of usual blood pressure to vascular mortality: a meta-analysis of individual data for one million adults in 61 prospective studies. Lancet. 2002;360(9349):1903-1913.

5. Wolf-Maier K, Cooper RS, Kramer H, et al. Hypertension treatment and control in five European countries, Canada, and the United States. Hypertension. 2004;43(1):10-17.

6. Wang YR, Alexander GC, Stafford RS. Outpatient hypertension treatment, treatment intensification, and control in Western Europe and the United States. Arch Intern Med. 2007;167(2):141-147.

7. Mancia G, Grassi G. Systolic and diastolic blood pressure control in antihypertensive drug trials. J Hypertens. 2002;20(8):1461-1464.

8. Franklin SS, Jacobs MJ, Wong ND, L'Italien GJ, Lapuerta P. Predominance of isolated systolic hypertension among middle-aged and elderly US hypertensives: analysis based on National Health and Nutrition Examination Survey (NHANES) III. Hypertension. 2001;37(3):869-874.

9. Williams B, Lindholm LH, Sever P. Systolic pressure is all that matters. Lancet. 2008;371(9631):2219-2221.

10. Bramlage P. Clinical practice and recent recommendations in hypertension management - reporting a gap in a global survey of 1259 primary care physicians in 17 countries. Current Medical Research and Opinions. 2007;23 (4):783-791.

11. McCombs JS, Nichol MB, Newman CM, Sclar DA. The costs of interrupting antihypertensive drug therapy in a Medicaid population. Med Care. 1994;32(3):214-226.

12. Jones JK, Gorkin L, Lian JF, Staffa JA, Fletcher AP. Discontinuation of and changes in treatment after start of new courses of antihypertensive drugs: a study of a United Kingdom population. $B M J$. 1995;311(7000):293-295.

13. Waeber B, Burnier M, Brunner HR. Compliance with antihypertensive therapy. Clin Exp Hypertens. 1999;21(5-6):973-985.

14. Mancia G, De Backer G, Dominiczak A, et al. Guidelines for the Management of Arterial Hypertension: The Task Force for the Management of Arterial Hypertension of the European Society of Hypertension (ESH) and of the European Society of Cardiology (ESC). J Hypertens. 2007;25(6):1105-1187.

15. Chobanian AV, Bakris GL, Black HR, et al. The Seventh Report of the Joint National Committee on Prevention, Detection, Evaluation, and Treatment of High Blood Pressure: the JNC 7 report. JAMA. 2003;289(19):2560-2572.

16. American Diabetes Association. Standards of medical care in diabetes. Diabetes Care. 2004;27(Suppl 1):S15-S35.

17. Hansson L, Zanchetti A, Carruthers SG, et al. Effects of intensive blood-pressure lowering and low-dose aspirin in patients with hypertension: principal results of the Hypertension Optimal Treatment (HOT) randomised trial. HOT Study Group. Lancet. 1998;351(9118):1755-1762.

18. Jamerson KA, Bakris GL, Wun CC, et al. Rationale and design of the Avoiding Cardiovascular events through COMbination therapy in Patients Living with Systolic Hypertension (ACCOMPLISH trial): the first randomized controlled trial to compare the clinical outcome effects of first-line combination therapies in hypertension. Am J Hypertens. 2004;17(9):793-801.
19. Lewis EJ, Hunsicker LG, Clarke WR, et al. Renoprotective effect of the angiotensin-receptor antagonist irbesartan in patients with nephropathy due to type 2 diabetes. $N$ Engl J Med. 2001;345(12):851-860.

20. K/DOQI clinical practice guidelines on hypertension and antihypertensive agents in chronic kidney disease. Am J Kidney Dis. 2004;43(5 Suppl 1): S1-S290.

21. Law MR, Wald NJ, Morris JK, Jordan RE. Value of low dose combination treatment with blood pressure lowering drugs: analysis of 354 randomised trials. BMJ. 2003;326(7404):1427.

22. Kochar M, Guthrie R, Triscari J, Kassler-Taub K, Reeves RA. Matrix study of irbesartan with hydrochlorothiazide in mild-to-moderate hypertension. Am J Hypertens. 1999;12(8 Pt 1):797-805.

23. Gerbino PP, Shoheiber O. Adherence patterns among patients treated with fixed-dose combination versus separate antihypertensive agents. Am J Health Syst Pharm. 2007;64(12):1279-1283.

24. Dickson M, Plauschinat CA. Compliance with antihypertensive therapy in the elderly: a comparison of fixed-dose combination amlodipine/ benazepril versus component-based free-combination therapy. $A m J$ Cardiovasc Drugs. 2008;8(1):45-50.

25. Bangalore $\mathrm{S}$. Fixed-dose combination improves medication compliance. J Clin Hypertens (Greenwich). 2006;(Suppl A):A72.

26. Jamerson K, Weber MA, Bakris GL, et al. Benazepril plus amlodipine or hydrochlorothiazide for hypertension in high-risk patients. $N$ Engl $J$ Med. 2008;359(23):2417-2428.

27. Bakris GL, Toto RD, McCullough PA, Purkayastha D, Davis P. Effects of different ACE inhibitor combinations on albuminuria: results of the GUARD study. Kidney Int. 2008;1303-1309.

28. Bakris G, Molitch M, Hewkin A, et al. Differences in glucose tolerance between fixed-dose antihypertensive drug combinations in people with metabolic syndrome. Diabetes Care. 2006;29(12):2592-2597.

29. Allemann Y, Fraile B, Lambert M, Barbier M, Ferber P, Izzo JL, Jr. Efficacy of the combination of amlodipine and valsartan in patients with hypertension uncontrolled with previous monotherapy: the Exforge in Failure after Single Therapy (EX-FAST) study. J Clin Hypertens (Greenwich). 2008;10(3):185-194.

30. Chrysant SG, Melino M, Karki S, Lee J, Heyrman R. The combination of olmesartan medoxomil and amlodipine besylate in controlling high blood pressure: $\mathrm{COACH}$, a randomized, double-blind, placebocontrolled, 8-week factorial efficacy and safety study. Clin Ther. 2008;30(4):587-604.

31. Avalide prescribing information. 2007. Available from: www.avaproavalide.com/pi_pop.aspx.

32. CoAprovel summary of product characteristics. 2007. Available from: emc.medicines.org.uk/emc/assets/c/html/DisplayDoc. asp?DocumentID=15112.

33. Raskin P, Guthrie R, Flack J, Reeves R, Saini R. The long-term antihypertensive activity and tolerability of irbesartan with hydrochlorothiazide. J Hum Hypertens. 1999;13(10):683-687.

34. Littlejohn T, III, Saini R, Kassler-Taub K, Chrysant SG, Marbury T. Long-term safety and antihypertensive efficacy of irbesartan: pooled results of five open-label studies. Clin Exp Hypertens. 1999;21(8):1273-1295.

35. Marino MR, Langenbacher K, Ford NF, Uderman HD. Pharmacokinetics and pharmacodynamics of irbesartan in healthy subjects. J Clin Pharmacol. 1998;38(3):246-255.

36. Schindler C, Ferrario CM. Olmesartan for the treatment of arterial hypertension. Future Cardiol. 2008;4(4):357-372.

37. Marino M, Lagenbacher K. Effect of hydrochlorothiazide on the pharmacokinetics and pharmadodynamics of angiotensin II blocker irbesartan. Drug Invest. 1997;383-391.

38. Coca A, Calvo C, Sobrino J, et al. Once-daily fixed-combination irbesartan $300 \mathrm{mg}$ /hydrochlorothiazide $25 \mathrm{mg}$ and circadian blood pressure profile in patients with essential hypertension. Clin Ther. 2003;25(11):2849-2864.

39. Bobrie G, Delonca J, Moulin C, Giacomino A, Postel-Vinay N, Asmar R. A home blood pressure monitoring study comparing the antihypertensive efficacy of two angiotensin II receptor antagonist fixed combinations. Am J Hypertens. 2005;18(11):1482-1488. 
40. Neutel JM, Smith D. Ambulatory blood pressure comparison of the anti-hypertensive efficacy of fixed combinations of irbesartan/ hydrochlorothiazide and losartan/hydrochlorothiazide in patients with mild-to-moderate hypertension. J Int Med Res. 2005;33(6): $620-631$.

41. Neutel JM, Saunders E, Bakris GL, et al. The efficacy and safety of low- and high-dose fixed combinations of irbesartan/hydrochlorothiazide in patients with uncontrolled systolic blood pressure on monotherapy: the INCLUSIVE trial. J Clin Hypertens (Greenwich). 2005;7(10):578-586.

42. Sowers JR, Neutel JM, Saunders E, et al. Antihypertensive efficacy of Irbesartan/HCTZ in men and women with the metabolic syndrome and type 2 diabetes. J Clin Hypertens (Greenwich). 2006;8(7):470-480.

43. Ofili EO, Ferdinand KC, Saunders E, et al. Irbesartan/HCTZ fixed combinations in patients of different racial/ethnic groups with uncontrolled systolic blood pressure on monotherapy. J Natl Med Assoc. 2006;98(4):618-626.

44. Cushman WC, Neutel JM, Saunders E, et al. Efficacy and safety of fixed combinations of irbesartan/hydrochlorothiazide in older vs younger patients with hypertension uncontrolled with monotherapy. Am J Geriatr Cardiol. 2008;17(1):27-36.

45. Saunders E, Cable G, Neutel J. Predictors of blood pressure response to angiotensin receptor blocker/diuretic combination therapy: a secondary analysis of the irbesartan/hydrochlorothiazide blood pressure reductions in diverse patient populations (INCLUSIVE) study. J Clin Hypertens (Greenwich). 2008;10(1):27-33.

46. Neutel JM, Franklin SS, Oparil S, Bhaumik A, Ptaszynska A, Lapuerta P. Efficacy and safety of irbesartan/HCTZ combination therapy as initial treatment for rapid control of severe hypertension. $J$ Clin Hypertens (Greenwich). 2006;8(12):850-857.

47. Franklin SS, Neutel JM, Donovan M, Bouzamondo H. Irbesartan/hydrochlorothiazide as initial therapy: subanalysis in patients with systolic $\mathrm{BP}>180 \mathrm{mmHg}$ and diastolic BP $>110 \mathrm{mmHg}$, efficacy and safety. J Hypertens. 2008;(Suppl 1):S159.

48. Neutel JM, Franklin SS, Lapuerta P, Bhaumik A, Ptaszynska A. A comparison of the efficacy and safety of irbesartan/HCTZ combination therapy with irbesartan and HCTZ monotherapy in the treatment of moderate hypertension. J Hum Hypertens. 2008;22:266-274.

49. Franklin S, Lapuerta P, Cox D, Donovan M. Initial combination therapy with irbesartan/hydrochlorothiazide for hypertension: an analysis of the relationship between baseline blood pressure and the need for combination therapy. J Clin Hypertens (Greenwich). 2007;9(12 Suppl 5):15-22.
50. Weir MR, Neutel JM, Bhaumik A, de Obaldia ME, Lapuerta P. The efficacy and safety of initial use of irbesartan/hydrochlorothiazide fixed-dose combination in hypertensive patients with and without high cardiovascular risk. J Clin Hypertens (Greenwich). 2007;9(12 Suppl 5):23-30.

51. Sun NL, Jing S, Chen J. [The control rate of irbesartan/hydrochlorothiazide combination regimen in the treatment of Chinese patients with mild to moderate hypertension]. Zhonghua Xin Xue Guan Bing Za Zhi. 2005; 33(7):618-621.

52. Schmieder RE, Krekler M. [Observational study of blood pressure control and microalbuminuria in type 2 diabetics on irbesartan or irbesartan/HCTZ]. MMW Fortschr Med. 2005;147 Suppl 3:97-101.

53. Strutz F, Bramlage P, Paar WD. Effect of three months' treatment with irbesartan on blood and pulse pressure of hypertensive type 2 diabetic patients: open, observational study in 31,793 patients. Curr Med Res Opin. 2005;21(9):1433-1440.

54. Sharma AM, Bramlage P, Kirch W. Antihypertensive effect of irbesartan and predictors of response in obesity-associated hypertension: a prospective, open-label study. Clin Drug Investig. 2005;25(12):765-776.

55. Schrader J, Bramlage P, Luders S, Thoenes M, Schirmer A, Paar DW. BP goal achievement in patients with uncontrolled hypertension: results of the treat-to-target post-marketing survey with irbesartan. Clin Drug Investig. 2007;27(11):783-796.

56. Kintscher U, Bramlage P, Paar WD, Thoenes M, Unger T. Irbesartan for the treatment of hypertension in patients with the metabolic syndrome: a sub analysis of the Treat to Target post authorization survey. Prospective observational, two armed study in 14,200 patients. Cardiovasc Diabetol. 2007;6:12.

57. Turnbull F. Effects of different blood-pressure-lowering regimens on major cardiovascular events: results of prospectively-designed overviews of randomised trials. Lancet. 2003;362(9395):1527-1535.

58. Weber MA, Julius S, Kjeldsen SE, et al. Blood pressure dependent and independent effects of antihypertensive treatment on clinical events in the VALUE Trial. Lancet. 2004;363(9426):2049-2051.

59. Franklin S, Lapuerta P, Cox D, Donovan M. Initial combination therapy with irbesartan/hydrochlorothiazide for hypertension: an analysis of the relationship between baseline blood pressure and the need for combination therapy. J Clin Hypertens (Greenwich). 2007; 9(12 Suppl):15-22.

60. Weir MR, Neutel JM, Bhaumik A, Obaldia ME, Lapuerta P. The efficacy and safety of initial use of irbesartan/hydrochlorothiazide fixed-dose combination in hypertensive patients with and without high cardiovascular risk. J Clin Hypertens (Greenwich). 2007;9(12 Suppl):23-30. 